\title{
Aprovechamiento del potencial turístico natural y cultural de El Colomo, Nayarit, como estrategia para su desarrollo local
}

\author{
David Israel González Valadez* \\ María Alicia Fonseca Morales \\ Universidad Autónoma de Nayarit \\ Alfredo César Dachary \\ Universidad de Guadalajara
}

\section{Resumen}

El Colomo es una localidad del municipio de Bahía de Banderas que se ubica en una zona privilegiada por importantes atractivos naturales, culturales e históricos factibles de aprovechamiento para actividades turísticas, como complemento de sus labores productivas tradicionales. Debido a que desde su incursión en el turismo ese municipio costero de Nayarit ha privilegiado el modelo de sol y playa, se considera una estrategia viable la implementación del turismo rural como un producto alternativo de gran potencial que, además de favorecer la diversificación de productos turísticos en la región -en particular los que demandan las nuevas preferencias asociadas al medio ambiente y al encuentro con otras culturas- fomenta la creación de la mediana y pequeña empresa que involucra directamente a las comunidades para el impulso de su desarrollo local.

Palabras clave

Desarrollo local, desarrollo sustentable, turismo rural, recursos naturales, El Colomo.

Recibido: 28/02/2014 · Aceptado: 04/05/2014

*Correos electrónicos: daves_8la@hotmail.com·afonseca2014@hotmail.com·alfredocesar7@ yahoo.com.mx 


\title{
Taking advantage of the natural and cultural touristic potential at EI Colomo, Nayarit as a local development strategy.
}

\author{
David Israel González Valadez* \\ María Alicia Fonseca Morales \\ Universidad Autónoma de Nayarit \\ Alfredo César Dachary \\ Universidad de Guadalajara
}

\begin{abstract}
El Colomo is a small town of the municipality of Bahía de Banderas located in a zone favored by important natural, cultural and historical attractions that make tourism activities feasible to complement traditional productive activities. Since its incursion into tourism, this coastal municipality in Nayarit has favored the sun and beach model and therefore the implementation of rural tourism as an alternative model is perceived as a strategy with great potential. It favors diversification of tourism products in the region -particularly those who attend new preferences associated with the environment and contact with other cultures- and fosters the creation of small and medium scale businesses that directly involve communities in promoting local development.
\end{abstract}

\section{KEY WORDS}

Local development, sustainable development, rural tourism, natural resources, El Colomo 


\section{Introducción}

La comunidad rural El Colomo (municipio Bahía de Banderas), enclavada en la región Costa Sur del estado de Nayarit, es privilegiada geográficamente por sus atractivos naturales, culturales e históricos, que la convierten en una localidad con gran potencial para la gestión de actividades alternativas relacionadas con el turismo rural que puedan significar un impulso real a su desarrollo local y al mismo tiempo representen un equilibrio respecto al modelo de desarrollo turístico de sol y playa predominante en esa región costera.

Desde mediados de los sesenta e inicios de los setenta diversos factores internos y externos incidieron en la selección de la región Costa Sur de Nayarit para implantar el turismo como la fuerza motriz de su economía y del desarrollo turístico alcanzado a la fecha, estos factores pueden agruparse en dos tipos: el primero se refiere a la infraestructura en comunicación terrestre y aérea principalmente, y el segundo se relaciona con las políticas nacionales -muy en boga en ese periodo- sobre la planificación de nuevos centros turísticos en distintos puntos del territorio nacional (Fonseca y de la Rosa, 2010: 166-167).

Con la Declaración Mundial sobre Ecoturismo (PNuma y омт, 2002: 2) se reconoce que el turismo trae consigo implicaciones económicas, sociales y medio mbientales, por lo que representa beneficios y problemáticas para el medio ambiente y las comunidades en que se realiza. Con todo, el ecoturismo es una opción sustentable frente al turismo tradicional, pues uno de sus principios es la conservación de los recursos naturales y la integración de las comunidades locales para que interactúen en una sola dirección: el desarrollo local y la sustentabilidad.

En particular, el turismo rural se reconoce como una oportunidad para potenciar áreas rurales que poseen valiosos recursos naturales, los cuales, asociados con la cultura de las comunidades, pueden ayudar a estas a enfrentar las dificultades económicas que en las últimas décadas, dentro del contexto de la globalización, se han vuelto cada vez más críticas. Vale la pena mencionar que, si bien la práctica del turismo rural tiene antecedentes históricos lejanos, las reflexiones sobre la pobreza en el campo presionaron a los gobiernos para concebir nuevas estrategias que paliaran esa situación.

La ausencia de desarrollo en el ámbito rural de los países de América Latina y las condiciones de pobreza y exclusión de gran parte de las comunidades 
campesinas llevaron a replantear la visión en torno a la propuesta de desarrollo rural aplicada durante más de dos décadas. A partir del año 2000, los gobiernos adecuaron sus políticas hacia una estrategia de desarrollo rural integrado con base en el enfoque territorial. En consecuencia, comenzaron a promocionar el desarrollo y la diversificación de actividades secundarias en el sector agropecuario (Román y Ciccolella, 2009: 9).

Una premisa fundamental para el impulso del desarrollo local mediante emprendimientos como el turismo rural es la participación directa de los agentes de la comunidad en un programa estratégico que involucre también actores públicos y privados, a fin de darle valor agregado a los recursos naturales y culturales con que se cuenta, así como a la cualificación laboral necesaria que aliente una sinergia virtuosa orientada al bienestar social de la comunidad.

El desarrollo local, entonces, se concibe como un proceso de cooperación y negociación entre actores en el que deben unirse fuerzas y recursos en modalidades de colaboración que estimulen y concreten iniciativas locales. La importancia del enfoque de desarrollo local es que se enmarca en los lineamientos del desarrollo sustentable, el cual se explica como un proceso de transformación de largo alcance, donde las prácticas de una sociedad se van modificando hacia el uso racional de los recursos.

El objetivo del estudio consistió en determinar alternativas de desarrollo local vinculadas al turismo rural en El Colomo. El trabajo in situ ha contado con la participación activa de la comunidad, sobre todo de los ejidatarios que tienen mucho interés en incorporarse a este tipo de actividades turísticas. Se consideran de gran trascendencia el análisis y la difusión del patrimonio natural y cultural que posee la región, así como el interés manifiesto de su comunidad por acceder a los apoyos públicos y financieros relacionados con la gestión de productos turísticos alternativos.

\section{Métodos e instrumentos}

El trabajo investigativo se realizó bajo un enfoque mixto, se combinaron los métodos inductivo y deductivo, así como técnicas cuantitativas y cualitativas, pero lo sustancial en el análisis de los resultados fue la percepción de lo cualitativo asociado al patrimonio natural y cultural de El Colomo. 
Se tuvieron en cuenta las propuestas metodológicas de Ceballos-Lascuráin (1998: 57-64), César y Arnaiz (2004: 53-54) y de la Secretaría de Turismo (Sectur, s. f.: 28-44), que coinciden en la elaboración de un inventario de recursos naturales y culturales y que aportan criterios de valoración sobre su estado de conservación y su calidad paisajística para uso turístico.

Debe señalarse que en todas las actividades realizadas durante la elaboración del diagnóstico y la caracterización del potencial turístico de El Colomo, así como en las propuestas que de ello derivaron, se atendieron los aspectos que la Comisión Nacional Forestal (Conafor, s. f.: 9-13) enfatiza como necesarios para el desarrollo local y regional en zonas forestales de uso común: incorporar en las actividades de monitoreo a las personas de la localidad que no cuentan con capacitación profesional especializada y que tienen distintos grados de conocimiento, experiencia, roles sociales e intereses, pues así se fortalece el núcleo social con el fin de aprovechar los bienes y servicios que el ecosistema les provee y para que los beneficios de las actividades recaigan principalmente en los ejidos y la comunidad.

El estudio implica las dimensiones social, económica y ambiental, mediante las variables: población, vivienda, infraestructura, educación, salud, economía y calidad del medio ambiente. Para cada dimensión se construyeron los indicadores pertinentes al caso de estudio. Asimismo, se diseñaron y aplicaron los instrumentos para la investigación de campo, que consistieron en: cédula para registro de recursos naturales y culturales, cuestionario dirigido a la población local y guía de entrevista a personajes representativos de la localidad y del sector turístico regional y estatal.

El trabajo in situ incluyó los aspectos esenciales que permitieron el acercamiento al objeto de estudio para su conocimiento:

a) Observación, identificación, reconocimiento y verificación de los componentes naturales y culturales de la zona. En estas actividades participó un grupo de campesinos nombrado por el comisariado ejidal El Colomo, quienes son los más interesados en promover el turismo rural.

b) Aplicación de la encuesta a la población local con el fin de definir el perfil de la comunidad respecto de los aspectos socioeconómicos, en particular sus capacidades productivas ligadas a sus tradiciones, así como las nuevas destrezas asociadas con los servicios turísticos. 
c) Realización de entrevistas a actores destacados de la comunidad, así como a funcionarios del sector turístico local, regional y estatal.

\section{El Colomo, Nayarit, y su potencial para el turismo rural}

\section{Localización}

El área de estudio que incluye a la comunidad El Colomo se localiza en el municipio Bahía de Banderas, en la región Costa Sur del estado de Nayarit. Está unida por la carretera ramal municipal de Mezcales, que comunica a Valle de Banderas (la cabecera municipal) y San Juan de Abajo. Sus coordenadas geográficas son: meridiano $105^{\circ} 09^{\prime} 25^{\prime \prime}$ de longitud oeste y el paralelo $20^{\circ} 52^{\prime} 08^{\prime \prime}$ de latitud norte, con altitudes mínima (50 msn) y máxima (1 $880 \mathrm{msn}$ ) en la sierra de Vallejo en el Valle de Banderas.

\section{Antecedentes históricos}

El nombre de El Colomo le viene de un árbol que abunda en la región; según la información de fuentes directas, los primeros indicios de asentamientos humanos en la zona datan de mediados del siglo xviII, época en que los hermanos Castañeda fundaron la hacienda El Colomo, la cual posteriormente vendieron a un mercader español llamado Ramón Maisterrena, quien la volvió muy próspera gracias al arduo trabajo de los avecindados en la zona.

El ejido El Colomo surge de la solicitud de vecinos de este poblado y de otros anexos que trabajaban para la hacienda, quienes manifestaban sus inconformidades sobre las precarias condiciones en que vivían; fue una lucha agraria iniciada desde 1927 y culminada en 1939 con la dotación de 3136 ha de tierra bajo el régimen ejidal ${ }^{1}$. En el transcurso del tiempo, la dotación inicial se ha modificado con base en diversos acuerdos de ampliaciones y expropiaciones con fines sociales, en la actualidad cuenta con una extensión territorial aproximada de 2,688-64-75.00 ha.

Su orografía incluye parte del Valle de Banderas y de una ladera de la Sierra Madre del Sur, específicamente en la porción circundante del Área de Protección

${ }^{1}$ Registro Agrario Nacional, Diario Oficial de la Federación, 31 de marzo de 1939. Archivos de dotación de ejidos, El Colomo y sus anexos. 
de Recursos Naturales Sierra de Vallejo, declarada así por la Comisión Nacional de Áreas Naturales Protegidas (Conanp, 2012) de la Secretaría de Medio Ambiente y Recursos Naturales (Semarnat).

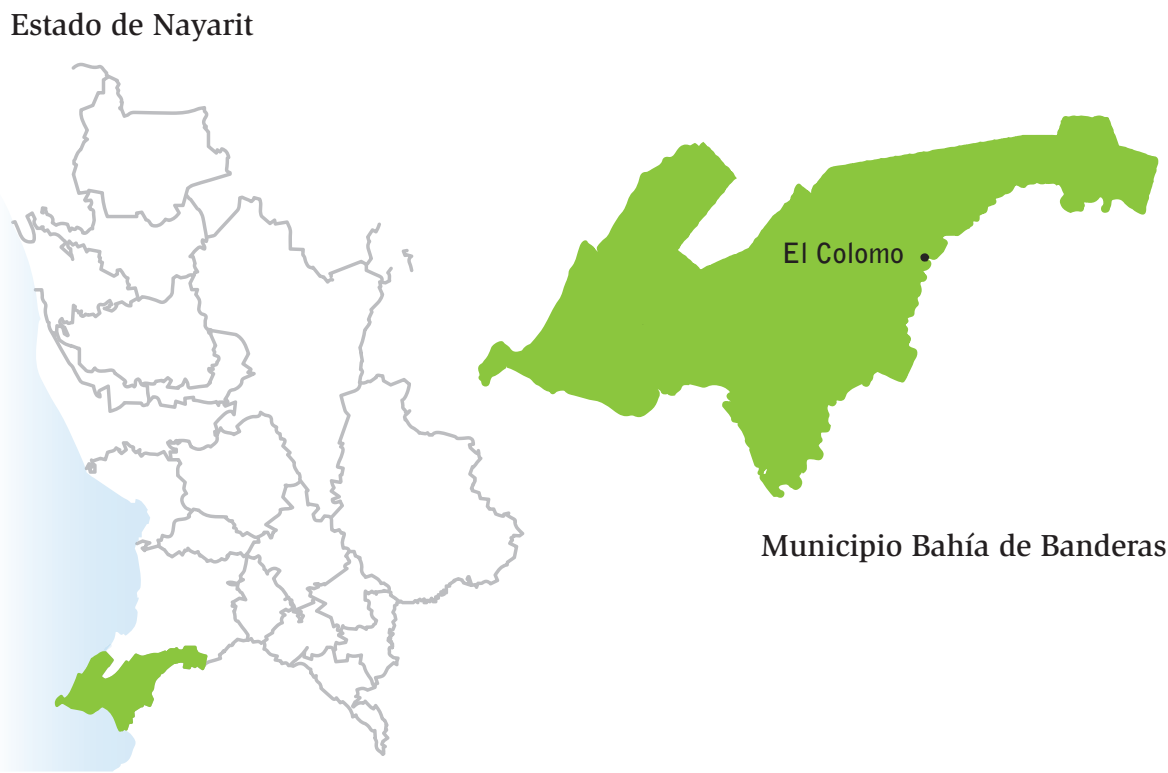

Fuente: Elaboración propia (con base en Mapas de México (INEGI, 2010).?)

Figura 1. Microrregión del área de estudio

\section{Aspectos socioeconómicos}

La localidad El Colomo está dentro de una línea de poblaciones rurales que van desde la zona costera hasta la sierra de Vallejo; en su mayoría se dedican a actividades primarias como la agricultura, la ganadería y el aprovechamiento forestal, con ingresos que, si bien les permiten subsistir, son insuficientes para crear el excedente necesario que les brinde estabilidad económica.

Sin embargo, puede observarse que, dada la cercanía de la localidad con el desarrollo turístico Riviera Nayarit, las jóvenes generaciones han incursionado en 
la prestación de servicios turísticos, en la industria de la construcción asociada a estos y en el comercio en general, con lo que perciben un ingreso extra que, aunque limitado, les ayuda a mejorar sus condiciones de vida y ha propiciado su arraigo local.

El Censo de Población y Vivienda 2010 (INEGi, 2010a) registró en El Colomo una población de 1496 habitantes en un total de 496 viviendas. A partir de estos datos, se tomó una muestra de 150 viviendas que, en conjunto, aportaron un total de 558 personas, de quienes se derivó el análisis de aspectos socioeconómicos que aquí se exponen de forma sucinta.

Cuadro 1. Crecimiento poblacional de El Colomo

\begin{tabular}{|l|ccc|}
\hline AÑo & 1990 & 2000 & 2010 \\
\hline POBLACIÓN & 1338 & 1076 & 1496 \\
\hline
\end{tabular}

Fuente: Elaboración propia con base en datos del INEGI (1990, 2000, 2010).

Para el logro de los objetivos planteados, la población muestra (558 personas) se subdividió en dos segmentos: a) habitantes mayores de 15 años de edad, considerados aptos para desempeñar un trabajo remunerado y cuyo registro captó en total 458 personas, que representan $82 \%$ de la población encuestada (de esta, 53 \% corresponde al sexo masculino y 47 \% al femenino); b) jóvenes menores de 15 años de edad (100 en total) que representan aproximadamente $18 \%$ de la muestra y quienes, por sus edades, son dependientes del segmento anterior.

Sobre el acceso a la vivienda se determinó que $89 \%$ de las viviendas son propiedad de quienes las habitan, $9 \%$ son prestadas por familiares y $2 \%$ son rentadas; esto refleja que la población tiene un elevado acceso a la vivienda. Se identificó, además, que cuentan con alrededor de $96 \%$ de cobertura en servicios de electricidad, agua entubada y drenaje.

Por sus características, las viviendas son diferenciadas; en cuanto a su tamaño, la mayoría son amplias, disponen de tres o cuatro cuartos y tienen corral (patio de tierra) con árboles frutales, aves de corral y cerdos. Se estimó un promedio de tres habitantes por vivienda, lo que denota una baja densidad de ocupación y, por lo tanto, mayor comodidad familiar. 
Según los parámetros internacionales, que establecen que con mejores materiales hay una mayor calidad de las viviendas, estas se clasificaron como de mediana calidad: $94 \%$ de las viviendas de El Colomo tienen paredes de ladrillo o block, pero en techos se comparten materiales: $40 \%$ son de concreto, $40 \%$ de lámina y $20 \%$ de palma; $89 \%$ de las viviendas tienen piso de mosaico y/o cemento y el resto de tierra. Respecto del equipamiento, $93 \%$ posee los aparatos y enseres más necesarios para la realización de las actividades domésticas cotidianas.

En cuanto a la cobertura de servicios urbanos, la localidad dispone de los servicios básicos de infraestructura: electricidad, agua entubada, drenaje, empedrado de calles, plaza pública y área deportiva; además de líneas telefónicas (Telmex), señal de telefonía celular y de internet. En general, la comunidad tiene buena opinión del cuidado de áreas públicas como el parque y las áreas deportivas, así como de los servicios religiosos, pero hay inconformidades sobre los servicios educativos de nivel preescolar, básico y medio básico, debido a que solo se ofrecen en turno matutino; y sobre el servicio de transporte público, porque no respeta los horarios establecidos, lo cual es causa de retrasos al desplazarse hacia los centros de trabajo. En materia de servicios de salud, la localidad tiene una clínica rural del Instituto Mexicano del Seguro Social (IMSS) que solo brinda servicio diurno, y una clínica dental de un médico particular. Sin embargo, puede afirmarse que, en general, los pobladores son saludables y han sabido conservar sus tradiciones alimenticias, pues sus padecimientos comunes se asocian a los cambios de clima estacional o a la vejez.

El acceso a la educación y el nivel educativo alcanzado en mayores de 15 años, son indicadores que inciden directamente en las oportunidades de desarrollo individual y colectivo en las comunidades. En ese sentido, la población menor de 15 años de edad presenta un oportuno acceso a los diferentes niveles educativos sea preescolar, primaria o secundaria. Por el contrario, la población mayor de 15 años de edad acusa serias limitaciones debido a que el porcentaje poblacional global por estudios concluidos representa solo $49 \%$ de ese segmento. La mayor concentración se observa en el nivel medio básico o secundaria concluida (21\%), en orden descendente le siguen el nivel básico o primaria terminada (14\%), y el nivel medio superior o bachillerato completo (9\%), los estudios profesionales concluidos muestran porcentajes muy bajos: $4 \%$ en licenciatura y $1 \%$ en carreras técnicas. 
Otro aspecto de análisis es cómo perciben los pobladores la integración social en su comunidad (gráfica 2) derivada de preguntas específicas que, aun con el

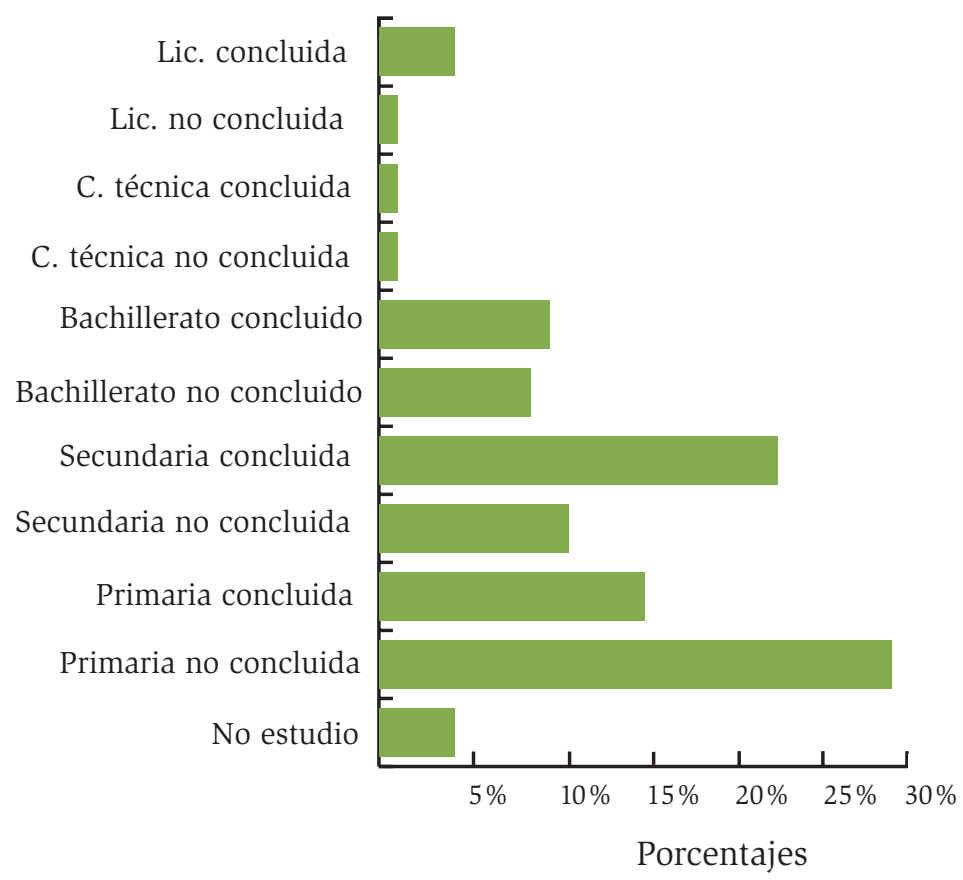

Fuente: Elaboración propia.

Gráfica 1. Población de El Colomo por nivel de estudios

grado de subjetividad que conllevan, son iluminadoras en cuanto a la cohesión social que persiste entre los habitantes de El Colomo, lo cual puede contribuir positiva o negativamente en la generación de nuevas estrategias de desarrollo local.

Con base en los resultados mostrados en la gráfica 2 es posible deducir una significativa integración social de los habitantes de El Colomo: 99 \% de 


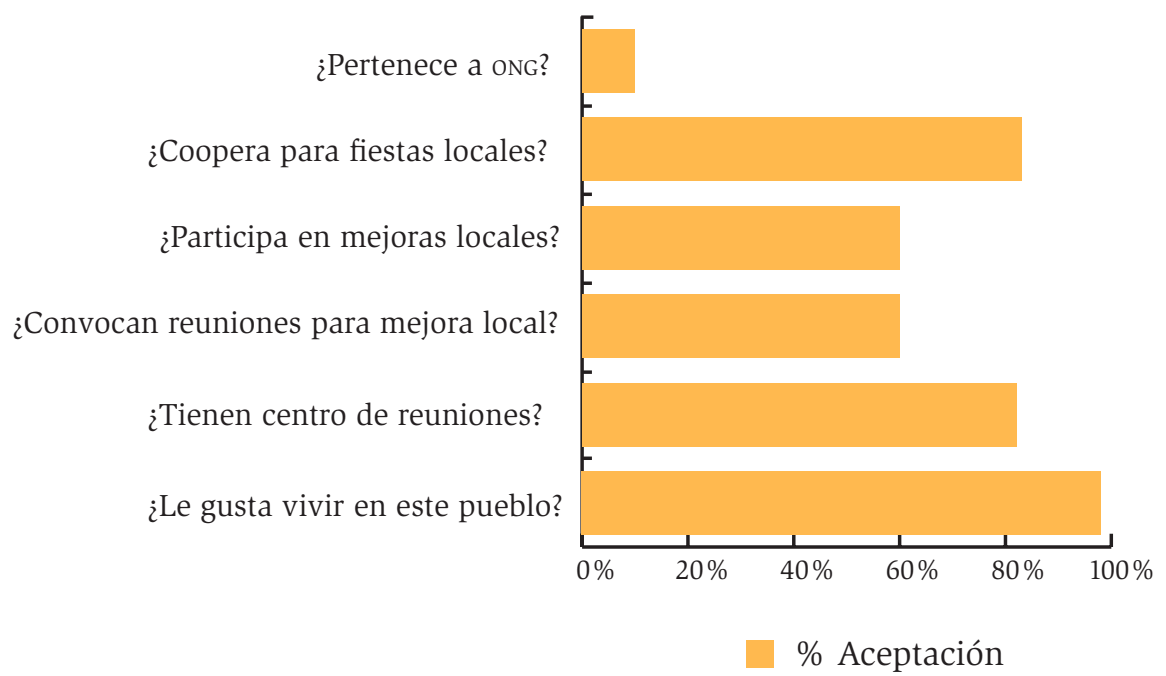

Fuente: Elaboración propia.

Gráfica 2. Formas de integración social El Colomo, Nayarit.

ellos expresaron satisfacción de vivir en esta localidad; también es notoria su participación en acciones de mejoramiento local, cooperan para sus eventos locales, y convivencias sociales. Además, 98 \% tiene una percepción positiva del desempeño de sus representantes locales, identificados por ellos mismos como el comisario ejidal y el juez auxiliar; en contraposición, no reconocen como autoridad local al delegado municipal, debido al poco trato que les otorga.

Por lo que se refiere a la variable economía (con la que se buscó conocer la participación de los pobladores en la economía local y regional, así como las áreas de su desempeño laboral), se analizaron aspectos relativos al acceso al trabajo remunerado de los 458 habitantes del segmento de mayores de 15 años de edad. De ellos, solo 52 \% realiza un trabajo remunerado, es decir, una proporción apenas ligeramente por encima de quienes no perciben ingresos por alguna actividad productiva, lo cual se traduce en un significativo nivel de dependencia económica familiar y, por ende, poca participación en la economía local y regional.

Según las actividades productivas que desempeña, se dividió a la población por sector económico (gráfica 3). El sector terciario concentra a la mayoría de 
las personas ocupadas de El Colomo (56\%), en especial en labores asociadas con los servicios turísticos y el comercio en general. Salen a trabajar a la franja costera del municipio, donde se impulsa el turismo de sol y playa, procuran los sitios que les quedan más cercanos como Bucerías, Punta de Mita y, sobre todo, Nuevo Vallarta. El sector primario le sigue en importancia, con $41 \%$ de la población, que cultiva principalmente maíz, arroz, frijol y sandía, y en menor escala se ocupa en la ganadería. El sector secundario tiene escasa representatividad en el empleo de los habitantes de El Colomo (3\%), quienes trabajan en la construcción en la zona turística.

La capacidad económica del núcleo familiar o de quienes residen en la misma vivienda se estimó a partir del total de los ingresos que aportan en conjunto para

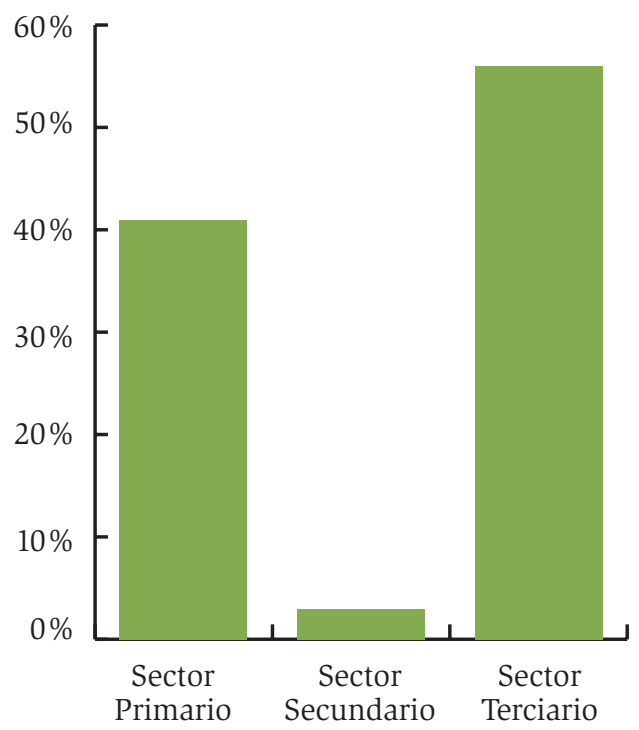

Fuente: Elaboración propia.

Gráfica 3.Población económicamente activa por sectores económicos, El Colomo, Nayarit. 


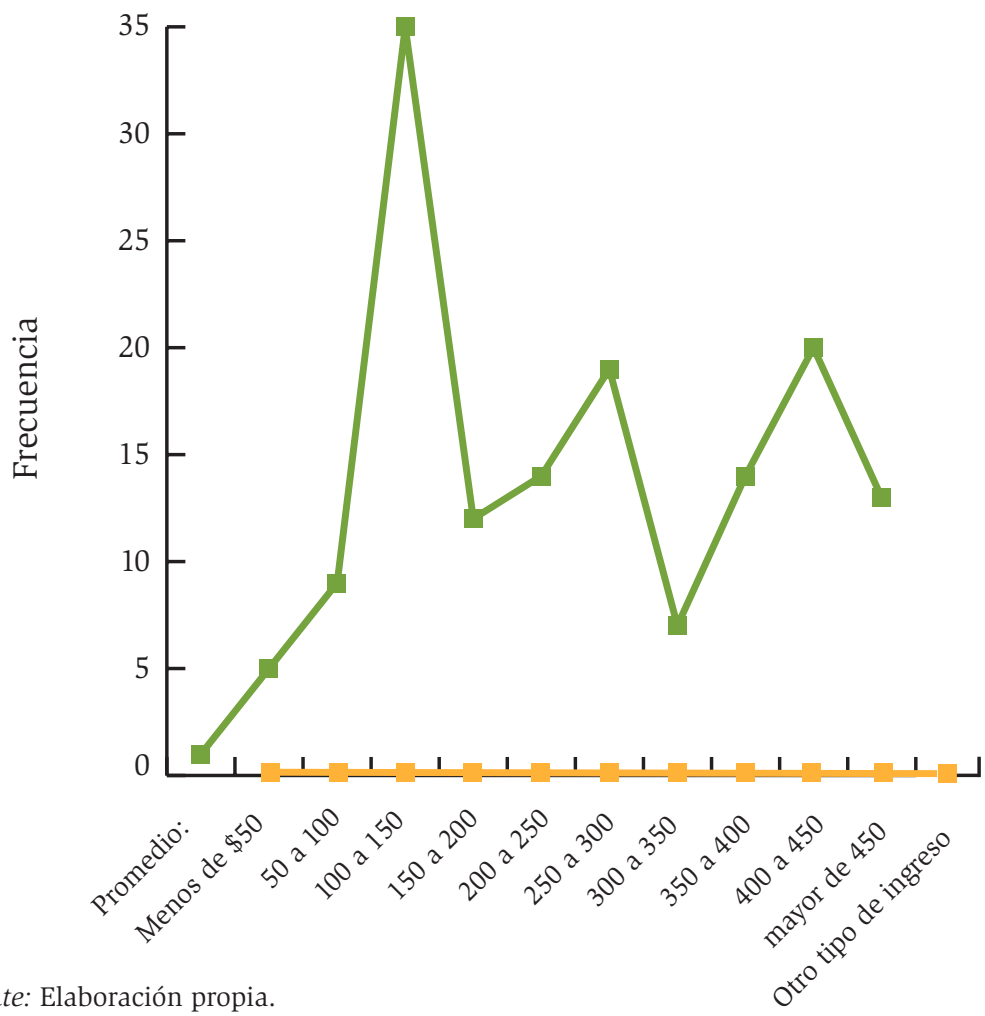

Gráfica 4. Ingresos diarios por unidad familiar. El Colomo, Nayarit.

solventar los gastos de las necesidades básicas y, de ser posible, otros de menor urgencia. Así, en alrededor de $11 \%$ de las viviendas la aportación conjunta de sus ocupantes con trabajo remunerado es menor a 150 pesos diarios, y si consideramos que el salario mínimo por día (smd) en la zona de Bahía de Banderas es de 63.77 pesos, entonces esos hogares sobreviven con 2.34 smd. El rango de aportación entre 150 y 200 pesos diarios alcanza $23 \%$, lo que da lugar al pico más alto que se muestra en la gráfica 4, y que escasamente supera los 3 smd para el sostenimiento familiar. El acumulado de frecuencias en rangos de ingresos superiores a 200 pesos por vivienda representa $57 \%$ del total, es decir, corresponde a más de la mitad de la población económicamente activa muestral y rebasa los 
4 smd en orden ascendente, aunque se presentan altibajos entre rangos. Por otra parte, en $9 \%$ de las viviendas los ocupantes son adultos mayores sin ingresos provenientes de un empleo remunerado en activo, viven de la pensión o de apoyos de sus familiares que, en su mayoría, trabajan en el extranjero.

Respecto a otros efectos del desarrollo turístico regional, se recogieron opiniones con un generalizado sentimiento de enojo y frustración por el atropello de algunas operadoras turísticas que realizan recorridos ecoturísticos dentro del territorio de El Colomo sin consultarlos o mediante algún convenio de colaboración y beneficio mutuo, incluso a veces hacen parada en la plaza del pueblo, pero los turistas no consumen nada por el estricto control de los guías.

Tal realidad ha motivado el interés de la población local por desarrollar ellos mismos actividades de turismo alternativo para aprovechar los recursos naturales y culturales que poseen, esa iniciativa ha sido encabezada por el comisariado ejidal mediante gestiones en diversas instancias públicas, en particular las que tienen que ver con programas de desarrollo rural. A la fecha se han logrado apoyos colaterales para el ejido, pero aún no cuentan con un proyecto específico sobre turismo.

Cabe destacar que $96 \%$ de los encuestados expresó su interés en que se implemente un proyecto de turismo con oportunidades para trabajar en actividades turísticas de hospedaje, preparación de alimentos y bebidas, de guías de turistas, servicio de taxi, venta de artesanías propias y otras que puedan surgir posteriormente. En general, la población está consciente de que deberán cuidar los recursos naturales, pues serían el principal atractivo para los turistas, y por ello $4 \%$ de los encuestados no desean traer turismo a su localidad, pues consideran que en esas actividades predominan los impactos negativos sobre los positivos.

\section{Aspectos ambientales del área de estudio}

Las características físicas y biológicas del área de estudio; su clima, orografía, hidrología, flora y fauna silvestre le proveen abundantes recursos naturales, los cuales, combinados con las actividades que tradicionalmente desarrolla la comunidad, la fortalecen para integrar un importante catálogo de atractivos de naturaleza y cultura.

Clima. Es semicálido subhúmedo fresco, con lluvias en verano, el más húmedo es el de la zona AW 2 (W). La temperatura y precipitación pluvial promedio 
anual oscilan entre los 26 y los $28{ }^{\circ} \mathrm{C}$, y de $930.8 \mathrm{~mm}$ a $1688 \mathrm{~mm}$, respectivamente; el porcentaje de precipitación invernal varía de $3.1 \mathrm{~mm}$ a $6.1 \mathrm{~mm}$.

Suelo. La zona abarca aproximadamente $30 \mathrm{~km}$ de la planicie costera de Bahía de Banderas, tierra adentro al pie de la sierra de Vallejo, en el área del delta del río Ameca, en la zona conocida como Valle de Banderas, cuya extensión es de 75 km².

Historia del uso de suelo en la zona. De 1935 a la fecha las tierras están concesionadas al ejido para fines agrícolas y ganaderos. Parte de estas tierras en la zona de la sierra de Vallejo se dedican a la actividad forestal. En la actualidad, el uso del suelo se destina a las actividades agrícolas (en esencia a la siembra de maíz, frijol, chile, sandía, tabaco, soya, yaca y algunos cultivos perennes), abarcando alrededor de 7000 ha y a la cría de ganado, cuya actividad se compone $80 \%$ de ganado bovino, $15 \%$ porcino y $5 \%$ caprino. Con las actividades forestales en la parte media y alta de la sierra se benefician con fines comerciales de maderas preciosas como amapa, capomo, huanacaxtle, higuera, papelillo, entre otras, y de polines para la construcción.

Tipo de suelo en la zona. En términos geológicos consiste en un basamento de origen volcánico silícico en un conglomerado de clastos graníticos y capas de arenisca, en tobas soldadas cuyas características revelan que datan del Mioceno temprano o medio, aproximadamente.

Topografía. La zona de estudio se encuentra a una altitud mínima de 50 msn en la parte baja de la sierra de Vallejo, en el Valle de Banderas, y una máxima de 1 880 msn en la parte alta de la misma. La penetración del efecto costero hacia el continente tiene como frontera los cuatro sistemas montañosos que la rodean: la sierra de Vallejo al norte, la sierra El Cuale al este, la sierra El Tuito al sureste, y la sierra Lagunillas al sur. Todas estas, por su altitud, sirven de sistemas de captación de la humedad durante la época de lluvias, por lo cual se trata de una zona con una gran riqueza biológica vegetal.

Hidrología. La zona se encuentra en la región hidrológica 14, comprendida entre las coordenadas $20^{\circ} 48^{\prime} 122^{\prime \prime}$ latitud norte y $105^{\circ} 14^{\prime} 46^{\prime \prime}$ longitud oeste; limitada al suroeste por la delta del río Ameca y el arroyo El Chorrillo, que baja de la parte alta de la sierra. 
Flora y fauna. La vegetación de la zona es de relictos de selva mediana subcaducifolia, vegetación secundaria y acahual. En lo que respecta a la flora se pueden encontrar Acacia cochliacantha, Xylosma, Anthoxlum, Acalypha, huanacaxtle, primavera, amapa, pino, roble y encino. La fauna predominante está integrada por iguana verde, lagartija escamosa, garzón blanco, garza ganadera, codorniz crestidorada, pericos, conejos, armadillos, coyotes, zorra gris y gato montés.

A continuación se describen los recursos naturales y culturales con potencial turístico que, con adecuaciones mínimas, son viables para el desarrollo de actividades turísticas en el área estudiada.

\section{Recursos naturales y culturales con potencial turístico en El Colomo, Nayarit}

1. Arroyo El Chorrillo (recurso natural)
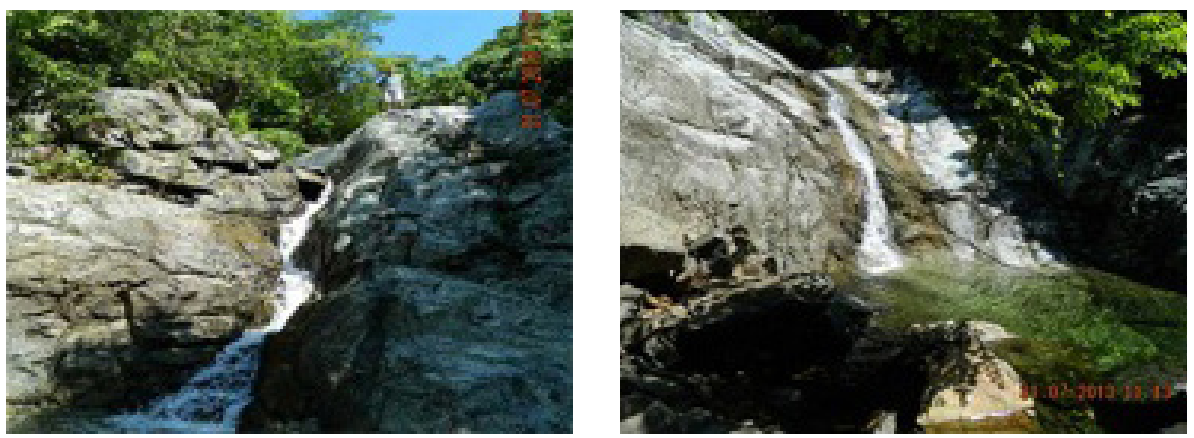

Figuras 1 y 2. Cascada principal y alberca natural

\section{Descripción}

El arroyo El Chorrillo se origina en las faldas del cerro Vallejo, ubicado a una distancia aproximada de $5 \mathrm{~km}$ de El Colomo; se puede acceder a la zona de cascadas por un camino de terracería que está en buenas condiciones, las cascadas cuentan con caídas de agua de casi $10 \mathrm{~m}$, desde la primera cascada hasta la cascada principal son cerca de $200 \mathrm{~m}$. El cauce del arroyo está rodeado de exuberante belleza, tiene una orientación de norte a sur y en el este se observan formaciones de fosas que visitantes de la región aprovechan como balneario recreativo. 


\section{Estado de conservación}

A la fecha no se ha modificado ni alterado por actividades humanas, por lo que conserva sus características naturales originales.

\section{Propuesta de aprovechamiento turístico}

- Construir cabañas rústicas y colocar asadores para la preparación de alimentos en la parte alta de El Chorrillo, en su costado izquierdo de norte a sur, donde existe un espacio plano de casi una hectárea adecuada para tales fines.

- Acondicionar pequeñas represas en la parte baja de las cascadas, que formarían albercas para ampliar las áreas del balneario natural, apto para el disfrute de turismo nacional y extranjero.

- Promocionar la realización de actividades como el rapel (descenso con cuerda fija y con auxilio de equipos y técnicas especializadas) o la tirolesa (cuerda o cable en tensión por la cual se desliza la persona por medio de una polea para cruzar de un lado a otro barrancos, ríos o cañadas), que hoy en día se utilizan como una modalidad para producir adrenalina y emociones de una manera muy segura y divertida. Esto puede llevarse a cabo a un costado de las cascadas donde se forma un acantilado de entre 30 y $40 \mathrm{~m}$ de altura.

- Impulsar el campismo; los amantes del contacto directo con la naturaleza pueden acampar en la parte baja.

\section{Exhacienda Maisterrena (recurso cultural)}

\section{Descripción}

Construcción del casco de la hacienda ubicada en el centro del poblado El Colomo, su fachada conserva el diseño original, aunque en su interior se han hecho modificaciones de conformidad con las necesidades de casa habitación actual.

\section{Estado de conservación}

Gran parte de la construcción de lo que fue hacienda ha sido destruida, sin embargo, aún quedan vestigios que dan cuenta de una historia antigua de El Colomo. 


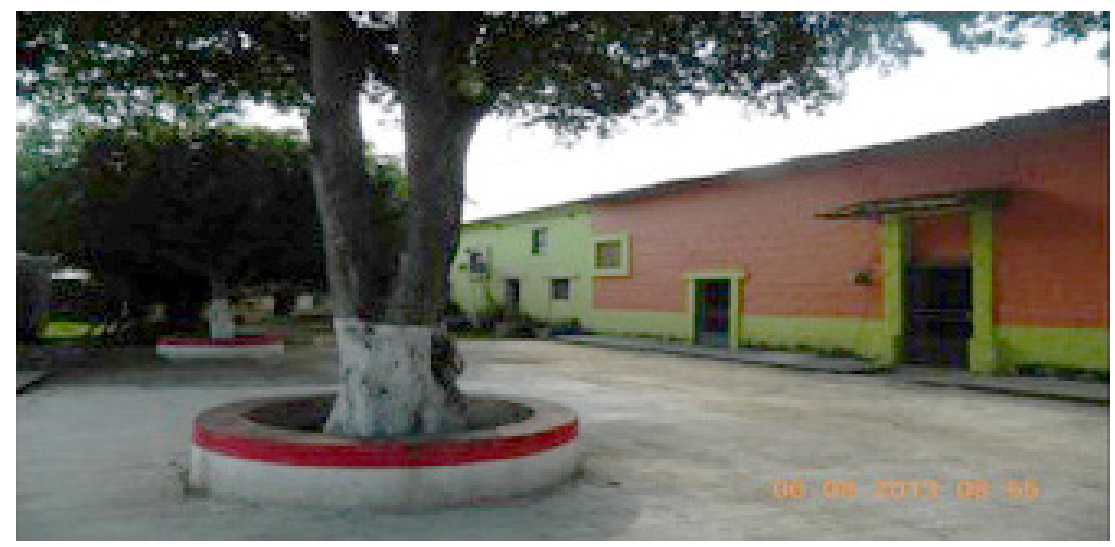

Figura 3. Exhacienda, fachada frontal

Propuesta de aprovechamiento turístico

- Realizar visitas guiadas a la exhacienda explicando detalles de su pasado y presente.

- Promover la fotografía rural, consistente en capturar imágenes de las diferentes manifestaciones culturales de las poblaciones rurales.

- En su exterior, se sugiere la construcción de un módulo de información turística, la venta de artesanías y un servicio de cafetería.

3. Presa las Gaviotas (recurso natural)

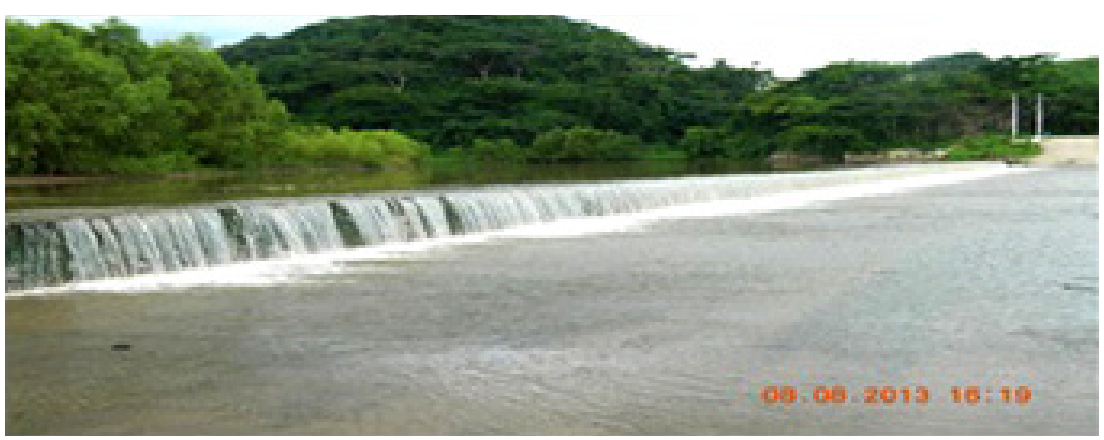




\section{Descripción}

Se ubica aproximadamente a $4 \mathrm{~km}$ de El Colomo, se puede llegar a la presa por un camino pavimentado. Es alimentada por el cauce del río Ameca y en ella es posible encontrar trucha, mojarra, cristalina, lisa, entre otras especies. La cortina de la presa mide un metro de altura por $250 \mathrm{~m}$ de longitud, lo que genera un espejo de agua abundante.

\section{Estado de conservación}

El agua está muy contaminada por residuos de basura (latas, bolsas, entre otros).

\section{Propuesta de aprovechamiento turístico}

- Implementar un programa de cuidado y conservación del recurso con base en la normativa ambiental vigente.

- Realizar pesca recreativa especial para los turistas que desean experimentar la sensación de extraer un pez de un cuerpo de agua (mar, río, lago, laguna, etc.); en esta práctica es común que una vez capturada la especie se reintegre a su medio.

- El abundante espejo de agua permite realizar kayaquismo (navegar en una embarcación de diseño hidrodinámico); deporte que se puede llevar a cabo en aguas en movimiento o quietas.

4. Árboles representativos en el ejido El Colomo (Recurso natural y cultural)
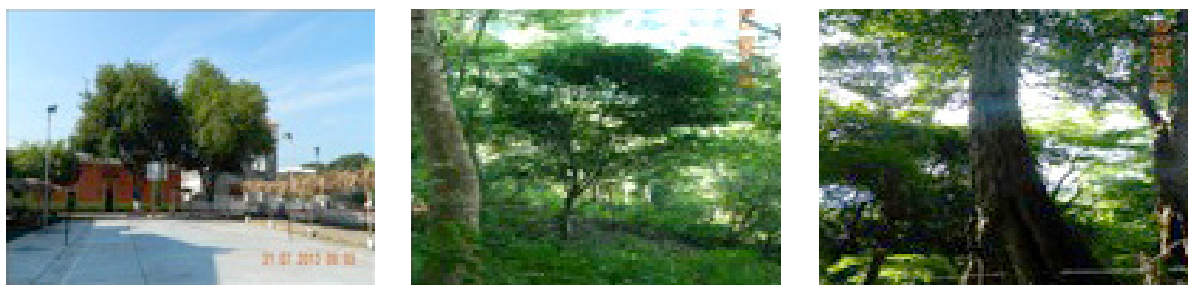

Figura 5, 6 y 7. Tamarindo, Limoncillo y Capomo 


\section{Descripción}

- En el centro del poblado hay dos árboles de tamarindo con una edad aproximada de 200 años.

- A $5 \mathrm{~km}$ de El Colomo, en las faldas de la sierra de Vallejo, se ubica un espacio de poco más o menos 20 ha, donde se da el árbol de Limoncillo (solo en este espacio de toda la región); da su fruto durante febrero y marzo. El clima que predomina en la zona es fresco todo el año.

- El árbol de capomo crece en toda el área de estudio, su fruto produce una semilla del mismo nombre.

Estado de conservación

El árbol de tamarindo y el limoncillo se encuentran en buen estado de conservación, mientras que el capomo está amenazado por la tala con fines madereros.

Propuesta de aprovechamiento turístico

- El árbol de tamarindo puede aprovecharse para actividades como la fotografía, así como para una pequeña remembranza histórica a cargo de guías turísticos.

- Establecer una Ruta del limoncillo mediante recorridos de cabalgata o caminata por los hermosos paisajes de las laderas de la sierra de Vallejo, cruzar arroyos, admirar flora y fauna y la aventura de sentirse en un espacio totalmente natural.

- Preparación y degustación de café de capomo. Del árbol de capomo se recuperan sus semillas y con ellas se puede elaborar café de capomo; esto es posible implementando talleres gastronómicos que permitan al turista conocer el proceso de extracción, molienda, preparación y degustación de este tipo de café, conocimiento ancestral conservado por los habitantes de El Colomo. 
5. Caminos, laderas, arroyos, montaña (Recurso natural)
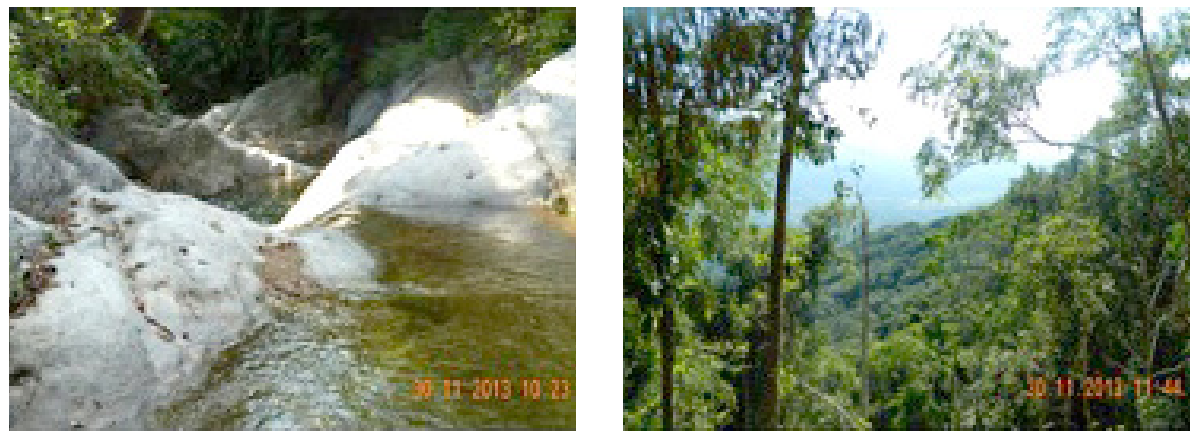

Figuras 9 y 10. Arroyo Piletas y montaña sierra de Vallejo

\section{Descripción}

Dentro de los límites del ejido existen caminos de terracería que van en diferentes direcciones, veredas hechas por el ganado o caminos sacacosechas que conectan con arroyos, cascadas y con el río Ameca, los cuales recorren la montaña e infinidad de paisajes naturales.

Estado de conservación

Los caminos y veredas necesitan solo un pequeño acondicionamiento, ya que su accidentada forma es su principal atractivo.

Propuesta de aprovechamiento turístico

- Ciclismo de montaña, con recorridos a campo traviesa por rutas previamente trazadas que cumplan con los lineamientos de la sustentabilidad.

- Cabalgata, recorridos a caballo por rutas preestablecidas que faciliten al turista montar y conocer el manejo y hábitos de estos animales, así como disfrutar de los diferentes paisajes naturales.

- Fotografía paisajística; aquellos turistas que disfrutan de este tipo de escenarios naturales pueden realizar esta actividad en la parte media alta de la sierra de Vallejo.

- Investigación científica de hábitats naturales de flora y fauna silvestre para su cuidado y aprovechamiento sustentable. 
6. Agricultura local (recurso natural y cultural)

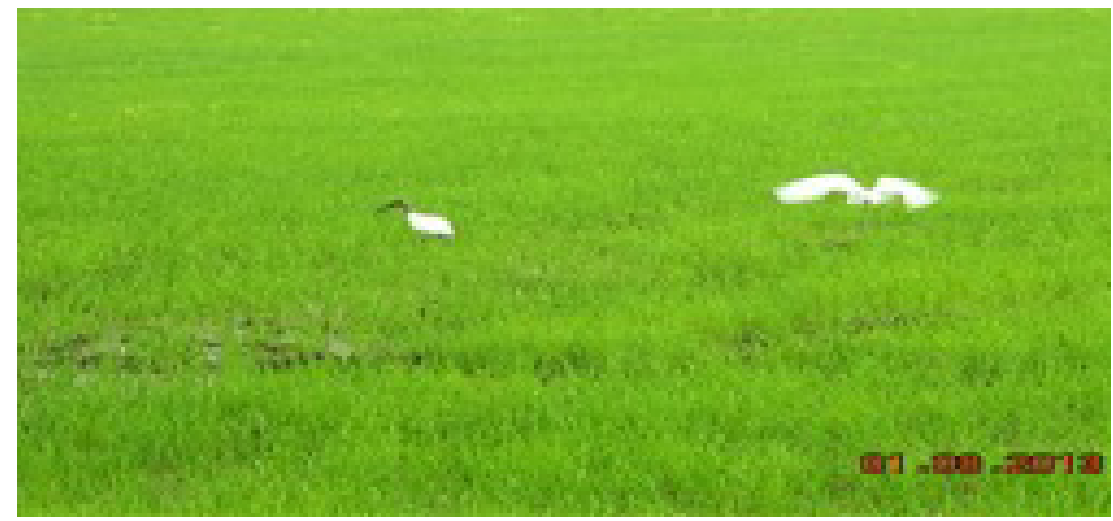

Figura 11. Sembradíos de arroz

\section{Descripción}

Dentro del ejido El Colomo se cultivan diferentes productos que además de su valor económico-agrícola proyectan hermosos paisajes locales: el maíz (de riego) se produce durante todo el año; el arroz (de temporal) se siembra en junio y julio y se cosecha en noviembre; el frijol (de riego) se trabaja de noviembre a febrero; la sandía (de riego) se cultiva en octubre, noviembre y diciembre y tarda de 70 a 80 días para producir

\section{Estado de conservación}

Son actividades agrícolas tradicionales y se producen al menos una vez por año.

Propuesta de aprovechamiento turístico

- Promover el agroturismo con un guía que explique el proceso de producción del recurso; se busca que la actividad represente una alternativa para que el campesino se beneficie con la expansión de su actividad económica mediante la combinación de la agricultura y el turismo.

- Fotografía del paisaje rural durante la época productiva.

- Organizar grupos de turistas para que participen en actividades agropecuarias. 
7. Fauna local (recurso natural)

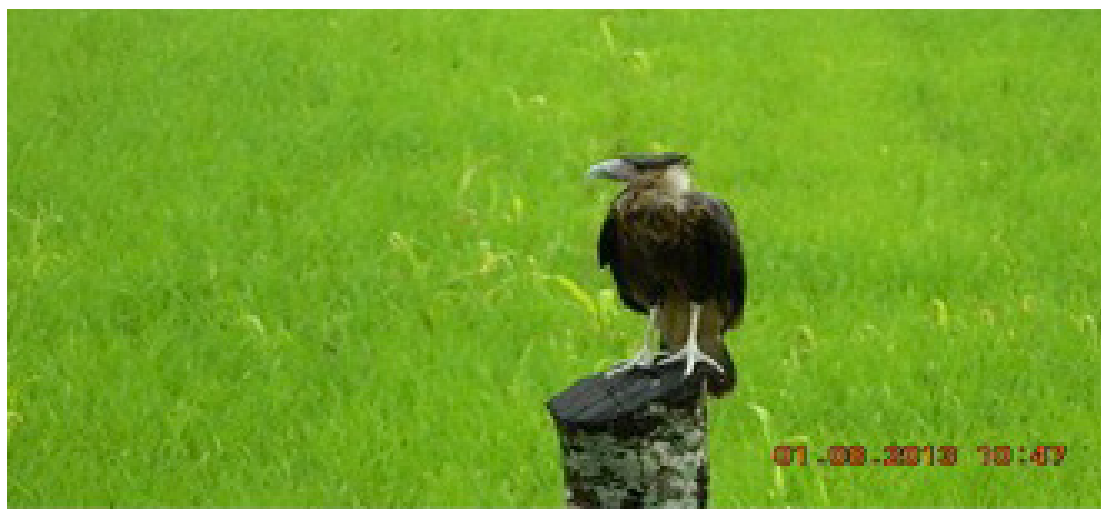

Figura 12. Ave que habita en los sembradíos (Caracara cheriway)

\section{Descripción}

Existen diversas especies en el área de estudio: venado, jabalí, jaguar, ardillas, guacamayas, águilas, las cuales enriquecen la belleza paisajística del lugar. Estado de conservación

Las especies de fauna que habitan en el área se encuentran amenazadas por la caza furtiva.

Propuesta de aprovechamiento turístico

- Observación de fauna silvestre, consistente en presenciar la vida animal en su hábitat natural, puede realizarse dentro de los límites del ejido.

- Fotografía de especies animales.

- Pintura paisajística.

8. Gastronomía local (ordeña) (recurso natural y cultural)

Descripción

Los derivados de la leche forman parte de la gastronomía local. El Colomo es una población agrícola-ganadera donde gran número de los habitantes tiene 

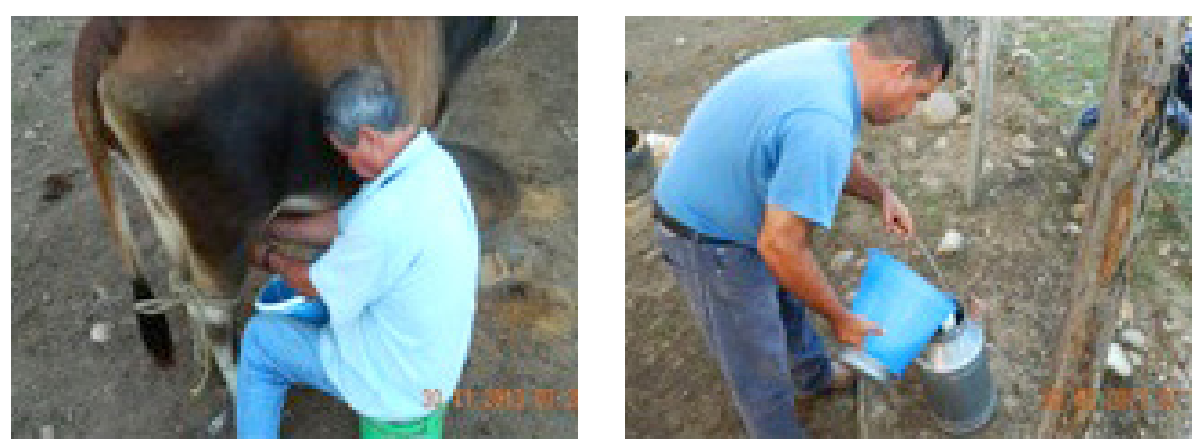

Figuras 13 y 14 . Ordeña

ganado, lo que permite realizar ordeña y preparar quesos maduros y frescos (panelas), jocoque, etcétera.

Estado de conservación

La ordeña y la producción de lácteos son actividades cotidianas que reflejan la conservación de la vida rural.

Propuesta de aprovechamiento turístico

- Motivar a los turistas para participar en las actividades de la ordeña.

- Talleres gastronómicos que permitan al visitante observar el proceso de elaboración de productos lácteos (desde la extracción de la leche mediante la ordeña hasta la preparación de quesos maduros, panelas, jocoque, etc.), a fin de que conozcan la gastronomía local y puedan degustar lo que se produce.

\section{Conclusiones}

Por su ubicación geográfica, la localidad El Colomo corresponde a la línea de poblaciones rurales que van de la zona costera hasta la sierra de Vallejo en Bahía de Banderas; por ello, desde tiempos remotos sus principales fuentes de sustento han estado relacionadas con la agricultura, la ganadería y el aprovechamiento forestal. Sin embargo, en décadas recientes, la inserción del turismo como práctica 
económica preponderante en la región costera ha modificado la dinámica laboral hacia otras oportunidades de empleo, reorientando a las nuevas generaciones hacia el giro turístico, con el consecuente abandono de las actividades económicas tradicionales.

Si bien en El Colomo han mejorado los ingresos familiares, estos no se han traducido en un desarrollo local significativo, es decir, a más de cuatro décadas del turismo de sol y playa en la región, las localidades como El Colomo (que son la mayoría en el municipio), no han sido vinculadas ni consideradas en el desarrollo turístico impulsado en la franja costera, asignatura que sexenio tras sexenio ha quedado como letra muerta en los planes de desarrollo de los tres órdenes de gobierno.

Con el argumento de significar un elevado ingreso de divisas, la clara racionalidad en que se mueve el turismo convencional (donde prevalece la rentabilidad del capital extranjero auspiciado por quienes toman las decisiones de las políticas de desarrollo) ha encauzado su esfuerzo a favorecer únicamente ese modelo y no da cabida a la participación de las comunidades en la actividad turística regional a fin de favorecer su desarrollo local.

La situación no es privativa de Nayarit, también ocurre en otras latitudes de México y de otros países que se disputan los grandes flujos de visitantes. Sin embargo, para El Colomo, puede representar ventajas y desventajas en relación con la intensa dinámica turística que vive Bahía de Banderas y la región en general.

- De las ventajas se destaca el carácter rural que aún conserva la comunidad: es gente sencilla, respetuosa y amable que mantiene estrechos lazos familiares y de convivencia; sus tradiciones culturales están asociadas en gran medida a las labores agropecuarias y de aprovechamiento forestal de bajo impacto, con excepción de los empleos tomados en la franja costera, sobre todo de baja cualificación.

- De las desventajas sobresale la dificultad para impulsar su economía local debido al poco apoyo brindado al campo en las últimas décadas; se percibe una frustración derivada de la marginación que sienten, porque aunque están relativamente cerca de una importante región turística esto no les ha reportado beneficios sustanciales. 
- Por otra parte, la población desconoce nuevas formas de aprovechamiento de su potencial (en términos de cultura y naturaleza) asociadas al turismo alternativo, como el ecoturismo o el turismo rural, para generar prácticas económicas que diversifiquen sus ingresos y mejoren sus condiciones de vida.

Con base en los trabajos realizados en el área de estudio se establecieron relaciones colaborativas directas con la población local, que posibilitaron reconocer las capacidades sociales y el potencial natural y cultural para, en el corto plazo, integrar un proyecto sobre turismo rural en concordancia con las actividades que tradicionalmente realizan como parte de su vida cotidiana, y con los lineamientos de sustentabilidad establecidos para su desarrollo.

Se considera que la zona posee un exuberante paisaje derivado de sus recursos naturales y una definida cultura tradicional, también existe la determinación de la comunidad, encabezada por el comisariado ejidal, de llevar adelante el proyecto. Estas fortalezas pueden favorecer el posicionamiento de El Colomo como una alternativa al turismo convencional, así como la gestión de apoyos significativos de diversos organismos públicos nacionales o internacionales que promuevan el turismo rural en cuanto opción acorde con las nuevas tendencias del turismo mundial, que conceden primacía al disfrute de la naturaleza y a la valoración de las actividades rurales. 


\section{Fuentes consultadas}

Ceballos-Lascuráin, H. (1998). Ecoturismo, naturaleza y desarrollo sostenible. México: Diana.

César, A. y S. Arnaiz (2004). Desarrollo y turismo en la costa de Jalisco. Guadalajara: Universidad de Guadalajara/Consejo Estatal de Ciencia y Tecnología del Estado de Jalisco.

Conafor (s. f.). Diagnóstico participativo. Métodos e instrumentos para realizar el diagnóstico participativo comunitario. México: Comisión Nacional Forestal/Secretaría de Medio Ambiente y Recursos Naturales (Serie Manual del Promotor, Capítulo 2).

Conanp (2012). Estudio previo justificativo para el establecimiento del área natural protegida con la categoría de Área Natural de Protección de Recursos Naturales "Sierra de Vallejo-Río Ameca", en los estados de Jalisco y Nayarit. México: Comisión Nacional de Áreas Naturales Protegidas.

Fonseca, M. A. y M. A. de la Rosa (2010). "Treinta años configurando el espacio turístico de Nayarit”. Revista de Economía, Sociedad, Turismo y Medio Ambiente, RESTMA, 11, 159-191.

INEGI (1990). XI Censo General de Población y Vivienda. México: Instituto Nacional de Estadística y Geografía.

----- (2000). XII Censo General de Población y Vivienda. México: Instituto Nacional de Estadística y Geografía.

(2010a). XIII Censo de Población y Vivienda. México: Instituto Nacional de Estadística y Geografía.

----- (2010b). Mapas de México [en línea]. México: Instituto Nacional de Estadística y Geografía. Disponible en: https://www.google.com.mx/se arch?newwindow $=1 \& q=$ mapa + de + mexico $+2010-e l+$ colomo + na yarit\&oq = mapa + de + mexico + 2010-el + colomo + nayarit\&gs_l $=$ ser p.12...67471.76948.0.79752.18.18.0.0.0.0.410.2516.0j13j1j0j1.15.0.ck ph...0...1.1.56.serp..10.8.1495.Nu8YAZI7qa0

омт (2002). Agenda 21 para la Industria de Viajes y Turismo: Hacia un Desarrollo Sustentable Ambientalmente. Madrid: Organización Mundial del Turismo.

PNuma y омт (2002). Declaración de Quebec sobre el Ecoturismo [en línea]. Cumbre Mundial del Ecoturismo celebrada en Quebec, Canadá. Programa 
de las Naciones Unidas para el Medio Ambiente/Organización Mundial del Turismo. Disponible en: http://www.cinu.org.mx/eventos/turismo2002/doctos/dec_quebec.pdf

Román, F. y M. Ciccolella (2009). Turismo rural en la Argentina. Concepto, situación y perspectivas. Buenos Aires: Instituto Interamericano de Cooperación para la Agricultura.

Sectur (s. f.). Identificación de potencialidades turísticas en regiones y municipios. México: Secretaría de Turismo (Serie de Documentos Técnicos en Competitividad, 8). 